\title{
Awareness of lifestyle modification in females diagnosed with polycystic ovarian syndrome in India: explorative study
}

\author{
Pothiraj Pitchai $^{1 *}$, S. R. Sreeraj ${ }^{2}$, Parmar Reema Anil ${ }^{3}$
}

\begin{abstract}
${ }^{1}$ Department of Community Physiotherapy, Maharashtra University of Health Sciences, Navi Mumbai, India
${ }^{2}$ Department of Musculoskeletal Physiotherapy, Maharashtra University of Health Sciences, Navi Mumbai, India

${ }^{3}$ Clinical Physiotherapist, Saxenas Physiotherapy clinic, Chembur East, Mumbai, India
\end{abstract}

Received: 28 December 2015

Revised: 31 December 2015

Accepted: 23 January 2016

\section{*Correspondence: \\ Dr. Pothiraj Pitchai, \\ E-mail: pothirajpt@gmail.com}

Copyright: (c) the author(s), publisher and licensee Medip Academy. This is an open-access article distributed under the terms of the Creative Commons Attribution Non-Commercial License, which permits unrestricted non-commercial use, distribution, and reproduction in any medium, provided the original work is properly cited.

\begin{abstract}
Background: Polycystic ovarian syndrome (PCOS) adversely affect women at varying stages of their life and imperative to emphasis on prevention strategies since incidence of PCOS is on the rise. Study aims to explore perception on PCOS, awareness on life style modification, emotional attributes, concern regarding PCOS and utilization of physiotherapy services.

Methods: The study was conducted in Mumbai and Navi Mumbai, India. Self-made validated questionnaire was administered. Descriptive analysis was done. Perception on PCOS, lifestyle modification, emotional attribution and biggest concern were calculated as absolute frequencies and were reported as overall percentages. Chi square test was applied on the demographic factor's influence on level of awareness.

Results: $21 \%$ of the respondents are very well aware about PCOS. 51\% reported as doctor was their main source of information about PCOS. $81 \%$ expressed that PCOS is manageable one. $62 \%$ aware that exercise helps in the management of PCOS. Out of this, 39\% are doing exercise on a regular basis. However all the study participants reported, they have not had any consultation from physiotherapist for their structured exercise program. $32 \%$ attributed to anxiety after the diagnosis of PCOS. $64 \%$ of the respondents aware that changing in diet or eating habits can influence in PCOS. However $95 \%$ of the subjects concurred to follow life style modification.

Conclusions: Efforts need to intensify in creating awareness on the general public about PCOS. Absolute majority of the study participant uncoerced to follow lifestyle modification however emphasis needs to address on multidisciplinary approach in managing PCOS.
\end{abstract}

Keywords: Polycystic ovarian syndrome, Awareness, Lifestyle modification, India

\section{INTRODUCTION}

Polycystic ovarian syndrome (PCOS) is a heterogeneous clinical entity leading to development of metabolic, endocrine and reproductive disorder. This multifaceted clinical manifestation comprises of hyperandrogenism, menstrual dysfunction, infertility, pregnancy complications and an increased prevalence of obesity and abdominal obesity. ${ }^{1}$ PCOS enact as risk factors in development of impaired glucose tolerance and cardiovascular diseases furthermore it is a significant cause of distress to most women affected by it. ${ }^{2-7}$

The pathogenesis of PCOS is complex and not completely understood. The underlying hormonal imbalance is created by a combination of increased androgens and/or insulin. Genetic and environmental contributors to hormonal disturbances with other factors 
including obesity, ovarian dysfunction and hypothalamic pituitary abnormalities are contribute to the etiology of PCOS. $^{8}$

PCOS women are at heightened risk of obesity, dyslipidemia and type II diabetes mellitus and may have an increased risk of cardiovascular disorder because of increased prevalence of subclinical atherosclerosis, hyperlipidaemia, hypertension, inflammation and endothelial dysfunction. ${ }^{8}$ It increases the risk of fetal deformities, miscarriages, and complications during pregnancy including premature deliveries and neonatal complications. ${ }^{9,10}$ PCOS also promotes psychological morbidity including depression, poor body image and self-esteem and reduced health related quality of life. ${ }^{11-13}$ Thus PCOS is associated with short term and long term presentations that may adversely affect women at varying stages of their life. Hence it is imperative in identifying effective therapies for the prevention and treatment of the syndrome to reduce its health and economic burdens.

Lifestyle modification have been proposed to improve not only metabolic and reproductive manifestation of PCOS but also yielding benefits including improvements in mood, self-esteem, anxiety, depression and psychological well-being. ${ }^{14-17}$ Lifestyle modification is the preferred first-line treatment for PCOS. The role and the effect of lifestyle modification are well documented in the literature. These non-pharmacological measures such as Diet and exercise are recommended as first-line of treatment in oligomenorrhea, hirsutism, infertility, and obesity in PCOS by the majority of endocrinologists and gynaecologists. ${ }^{18}$ Lifestyle modification, focus on dietary modification and increased physical activity and behavioural therapy, considered as important aspect in the management of PCOS. ${ }^{19}$ Physical exercises have been widely known to induce oxidative metabolism in tissues and the oxidative metabolism of the ovary is a stimulant for follicular development.

Maiya et al, 2008 stated, since weight loss by physical activity doesn't have potential side effects it should be addressed as first line of treatment. Graded aerobic exercise is a definite tool in decreasing the body weight in obese infertile women with PCOS also helps in reducing the cyst size, increasing the ovulation, and pregnancy rate. ${ }^{20}$ It is well known that exercise training improves an array of health-related outcomes, including protection against the development of Coronary Vascular Disease and diabetes, reduced morbidity and mortality also elevates psychological benefits. ${ }^{8}$ Wahrenberg et al in 1999 suggested a minimal amount of weight loss (5$10 \%$ ) over as little as 4 weeks is sufficient to improve the presentation of PCOS. ${ }^{21}$ Weight loss is thus a desirable outcome in overweight women with PCOS for treating both acute clinical and long-term metabolic health. Weight loss via energy restriction reinforce in the reductions in abdominal fat, blood glucose, blood lipids, and insulin resistance, improvements in menstrual cyclicity, ovulation and fertility, reductions in testosterone levels and free androgen index. ${ }^{8}$

This complex disorder affect both developed as well developing countries. Its prevalence ranges from 4\%$12 \%$ in general population of women in the world of reproductive age. ${ }^{22-28}$ Although there are no systemic studies from India, the observations by endocrinologists, gynaecologists, dermatologists, etc. show a significant rise in number of females with PCOS nevertheless prevalence of PCOS in Indian adolescents estimated at $9.13 \% .^{29}$ As PCOS incidence is on the rise in India a sense of urgency is needed in addressing this contemporary syndrome. Given the metabolic liabilities of PCOS and an increase in the adaptation of sedentary lifestyle and fast growing westernized diet culture in India this study aims to explore perception on PCOS among women with diagnosed PCOS, awareness on life style modification, their concern regarding PCOS and utilization of physiotherapy services.

\section{METHODS}

This is a cross sectional study conducted between the years of December 2014-May 2015. Subjects were recruited through purposive sampling method with the sample size of 100 who were visiting gynaecological clinics in and around Mumbai and Navi Mumbai, India. Women who was diagnosed as PCOS by a gynaecologist and reproductive age group between 18-35 years were only included in this study. Institutional ethical committee approval was obtained. Participants were explained about purpose of study and obtained their Consent. Self-made questionnaire was developed and validated from specialist in this field. To suite cultural differences Questionnaire was translated from English to Hindi with the help of linguistics. This self-made questionnaire then was circulated among the participants. Components of questionnaire consist of demographic details, Perception of PCOS, Awareness of exercise in PCOS, Emotions attributed to PCOS, Biggest concern with PCOS and willingness in Lifestyle modification. Chi square test was applied on the demographic factor's influence on level of awareness $P<0.05$ was considered statistically significant and descriptive statistics was done by using SPSS Statistical Software version 17 (SPSS Inc., Chicago, IL, USA).

\section{RESULTS}

100 unique, complete responses to the questionnaire were analyzed. Mean age of PCOS population were 23.38 \pm 4 .6. Total $9 \%$ of study participants were between age group of 30-35 years, $21 \%$ were $25-30$ and remaining $70 \%$ equally distributed in $21-25$ as well $18-20$ years. $51 \%$ of the subjects were students, $23 \%$ belongs to professional, housewife accounting for $14 \%, 7 \%$ house maid and $5 \%$ were unemployed. 
In level of awareness, $21 \%$ of the respondents indicated they had been informed well about PCOS and were very aware of it, $46 \%$ reported as somewhat aware, while $27 \%$ said minimally aware and $6 \%$ of them considered themselves as not at all aware. The influence of age on the level of awareness is not significant $(p=0.376)$ whereas association of occupation was highly significant ( $p=0.014)$. These influence of demographic factors on the level of awareness is shown in Table 1. Main source of information about PCOS was Doctor, Internet and Media which account for $51 \%, 22 \%, 14 \%$ respectively. $5 \%$ opted to family and 4\% shared Physiotherapist and friends individually as their source of information. Majority participant of $81 \%$ expressed that PCOS is manageable one. When asked about awareness on treatment option available for PCOS, 93\% responded as positive and $7 \%$ reported for negative response. Distribution of positive response frequency on the treatment option is shown in Figure 1. Only $84 \%$ of the participant was currently undergoing treatment and details of it shown in Figure 2.

Table 1: Impact of demographic factors on level of awareness using Chi-square test ( $p$ values set at $p<0.05$ ).

\begin{tabular}{|c|c|c|c|c|c|c|c|c|c|c|c|}
\hline \multirow{2}{*}{$\begin{array}{l}\text { p- } \\
\text { Value }\end{array}$} & \multicolumn{4}{|c|}{ Age Group } & \multirow{2}{*}{$\begin{array}{l}\text { Level of } \\
\text { Awareness }\end{array}$} & \multicolumn{5}{|c|}{ Occupation } & \multirow{2}{*}{$\begin{array}{l}\text { p- } \\
\text { Value }\end{array}$} \\
\hline & $30-35$ & $25-30$ & $20-25$ & $17-20$ & & Student & $\begin{array}{l}\text { House- } \\
\text { maid }\end{array}$ & $\begin{array}{l}\text { Un- } \\
\text { employed }\end{array}$ & Professional & $\begin{array}{l}\text { House- } \\
\text { wife }\end{array}$ & \\
\hline & $0.0 \%$ & $4.8 \%$ & $2.8 \%$ & $11.8 \%$ & Not at all & $2.2 \%$ & $\begin{array}{l}25.0 \\
\%\end{array}$ & $16.7 \%$ & $3.8 \%$ & $6.7 \%$ & \\
\hline & $44.4 \%$ & $42.9 \%$ & $25.0 \%$ & $14.7 \%$ & $\begin{array}{l}\text { Minimally } \\
\text { aware }\end{array}$ & $13.3 \%$ & $\begin{array}{l}37.5 \\
\%\end{array}$ & $33.3 \%$ & $34.6 \%$ & $46.7 \%$ & \\
\hline & $44.4 \%$ & $38.1 \%$ & $47.2 \%$ & $50.0 \%$ & $\begin{array}{l}\text { Somewhat } \\
\text { aware }\end{array}$ & $60.0 \%$ & $\begin{array}{l}37.5 \\
\%\end{array}$ & $33.3 \%$ & $26.9 \%$ & $46.7 \%$ & \\
\hline & $11.1 \%$ & $14.3 \%$ & $25.0 \%$ & $23.5 \%$ & Very aware & $24.4 \%$ & $0.0 \%$ & $16.7 \%$ & $34.6 \%$ & $0.0 \%$ & \\
\hline
\end{tabular}

Table 2: Frequency distribution of feelings attributed to diagnosis of PCOS by each age group.

\begin{tabular}{|l|lllllll|}
\hline $\begin{array}{l}\text { Age } \\
\text { Group }\end{array}$ & $\begin{array}{l}\text { Anxiety/ } \\
\text { worried }\end{array}$ & Depression/sadness & Frustration & Embarrassment & Hopelessness & Indifferent & Others \\
\hline $17-20$ & 21 & 8 & 6 & 8 & 5 & 4 & 1 \\
\hline $20-25$ & 22 & 12 & 15 & 5 & 4 & 7 & 6 \\
\hline $25-30$ & 7 & 10 & 3 & 5 & 1 & 3 & 0 \\
\hline $30-35$ & 2 & 1 & 2 & 3 & 2 & 0 \\
\hline
\end{tabular}

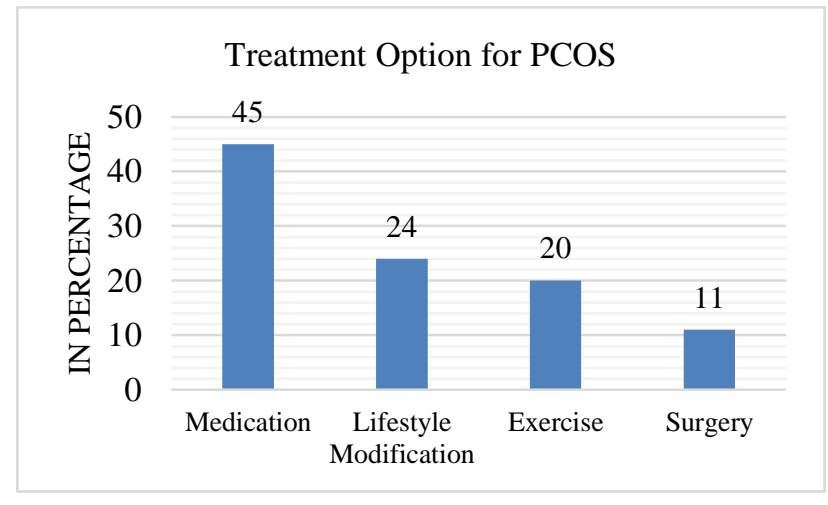

Figure 1: Availability of treatment option for PCOS.

$62 \%$ aware that exercise helps in the management of PCOS and their source of awareness majorly from their gynaecologist, internet and media which hold for $44 \%$, $19 \%$ and $16 \%$ respectively. In subjects who were aware of exercise helps in PCOS, 39\% are reported as doing exercise on a regular basis and their adopted exercise shown in Figure 3 where as $61 \%$ citing the reasons that refrains from doing exercise is shown in Figure 4. All study participants reported that they have not had any consultation from physiotherapist for their structured exercise despite $42 \%$ believed that exercise helps in weight reduction, $26 \%$ thought exercise helps in menstrual irregularity and their distribution is showed in Figure 5.

In Distribution of emotional feelings towards PCOS, anxiety placed on top followed by depression which secured $32 \%$, $19 \%$ respectively. Number of multiple responses obtained in each category according to age group is shown in table 2. Irregular periods and weight gain being their major concern in PCOS which demonstrated in Figure 6. However when analysed by each age group above mentioned remain constant except 
the age group of 25-30 who opted for difficulty in pregnancy followed by irregular period.

$64 \%$ of the respondents aware that changing in diet or eating habits can influence in PCOS out of which $46 \%$ altered their diet composition, 30\% reduced their energy or calorie intake, $17 \%$ on Weight maintenance regime and $7 \%$ said they increased physical activity. However $95 \%$ of the subjects concurred to follow life style modification besides their fertility drug and oral contraceptive pills.

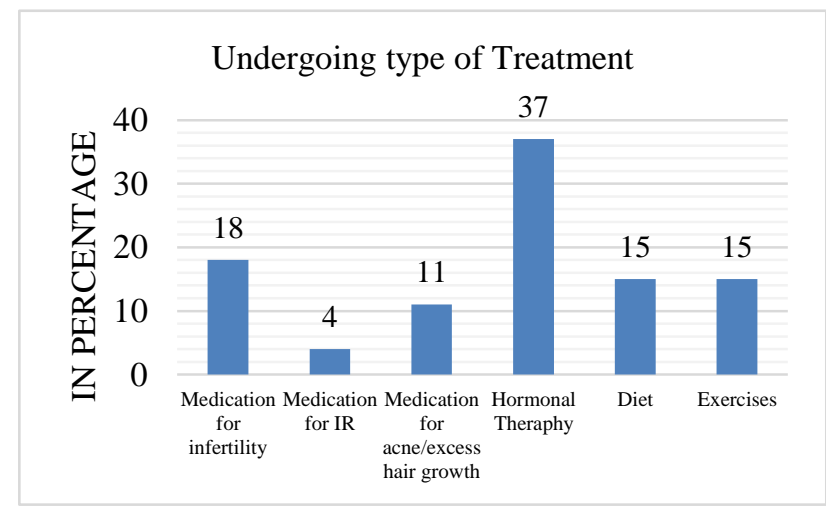

Figure 2: Treatment undertaken by the participants.

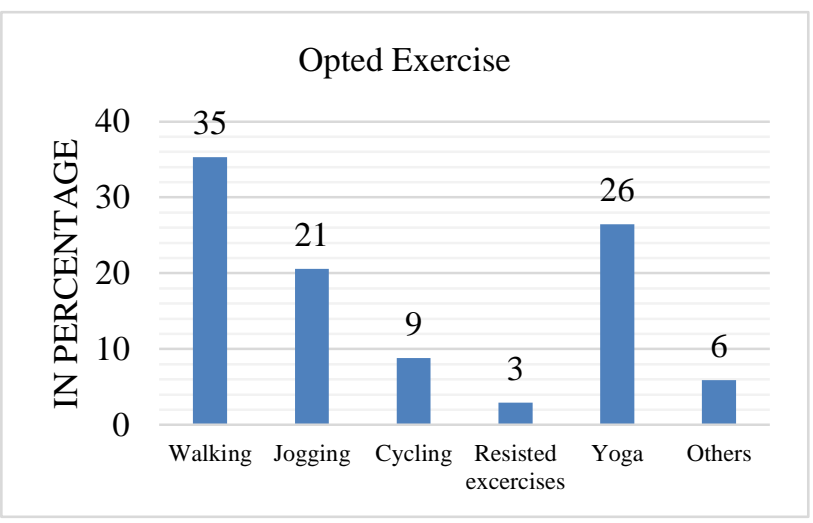

Figure 3: Exercise opted by the participants.

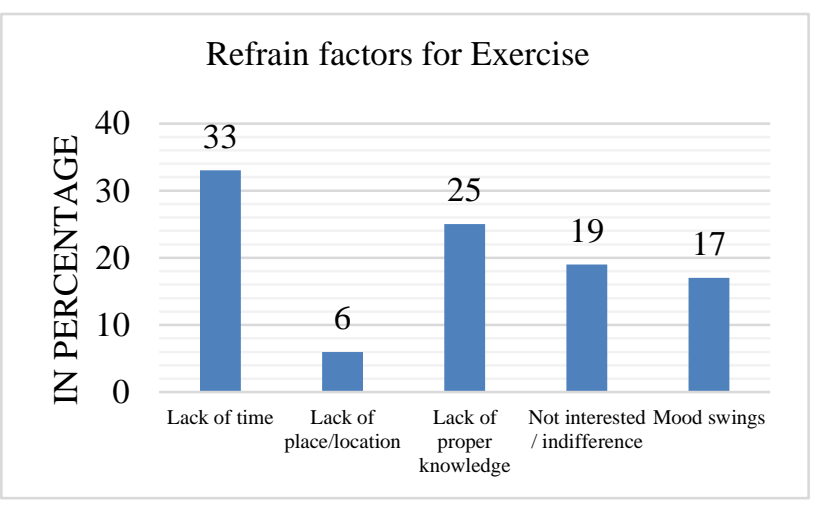

Figure 4: Refraining factors from doing exercise.

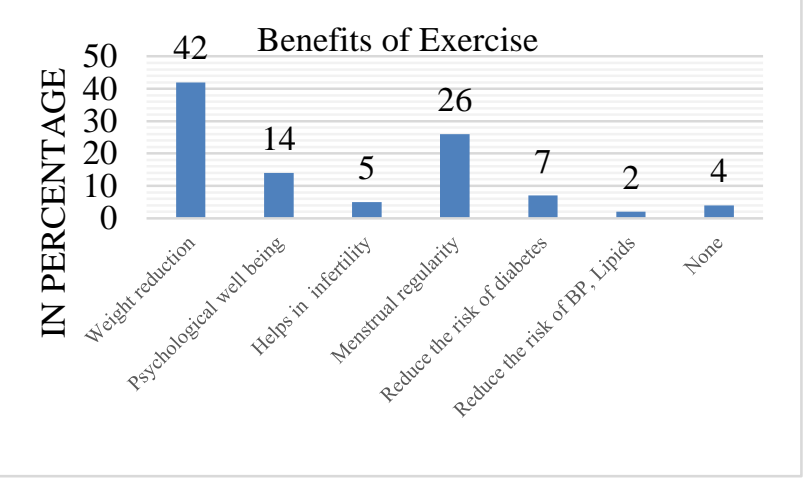

Figure 5: Benefits which can be obtained by doing exercise.

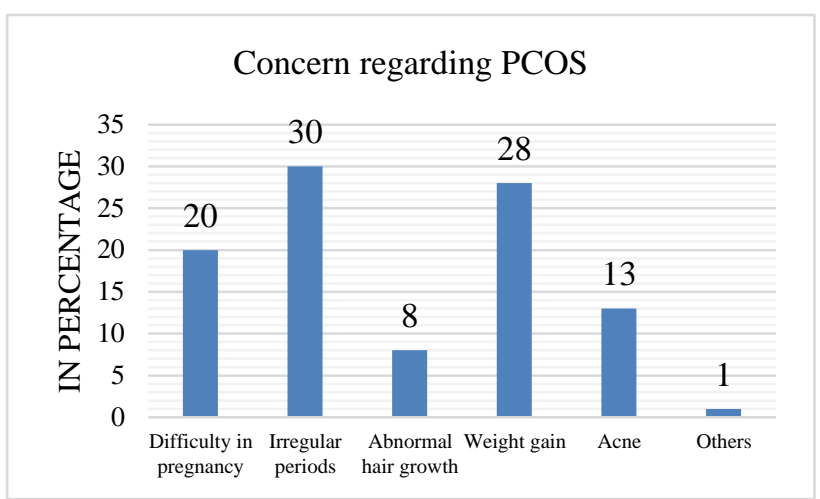

Figure 6: Biggest concern of PCOS by the participants.

\section{DISCUSSION}

On the perception of PCOS, this study demonstrate $21 \%$ of the participant were 'very aware' especially in the age group of 21-25 which comprised of professionals. Whereas $6 \%$ were not at all aware as they were unemployed/housemaids and also not much educated. A study by $\mathrm{E}$ Scott et all in reports that out of 657 participants more than $50 \%$ were completely aware about PCOS and according to his study physician was the main source of information among $63.5 \%$ whereas this study shows $51 \%$ which signifies physician plays an important role in imparting knowledge about PCOS. ${ }^{30} 21 \%$ opted for Internet for their knowledge about PCOS as $45 \%$ samples were students and $26 \%$ professionals. Data shows that $19 \%$ of people thought PCOS is not manageable due to loss of hope in some situations or due to no improvement in their condition, indifference about trying to manage or treat it and lacks of knowledge as some of them are uneducated. $7 \%$ were unaware of different treatment options available as no source of awareness about the same was made available to them being illiterate. Emotional disturbances and difference in attitude influenced $16 \%$ of the participant who did not undergo any kind of treatment as they were indifferent about the condition or had given up on trying as they saw no improvement and some were depressed and lost hope 
of it being further treated. Out of $84 \%$ who were currently undergoing treatment $20 \%$ indulged in some sort of exercise and majority belongs to students.

However this study reveals $62 \%$ aware about exercise which helps in PCOS and source being gynaecologist; however out of these only $39 \%$ exercise regularly and most of them have started exercising recently in spite of being diagnosed more than a year. This is because it took some time for the subjects to analyse and try to adhere to a specific type of treatment. Nevertheless $35 \%$ of them preferred only walking due to lack of time to do any other form of exercise but none followed any protocols for the same exercise. Despite of being aware of exercise that helps in managing PCOS $61 \%$ of the subjects were not exercising regularly especially professionals and students cited due to lack of time followed by lack of knowledge amongst housemaid, unemployed also students.

Emotional well-being of the subject with PCOS is well established in the past. E Scott et al study exhibits $66.5 \%$ attributed frustration to PCOS whereas this study reveals $32 \%$ feel anxious as they are not completely aware of what PCOS is and will they ever be able to manage it. $19 \%$ feel depressed as the distorted body image and altered quality of life hinder their mental state due to hormonal alterations slipping them into depression in PCOS.

In contrast to E Scott et al major concern of this study participants being irregular period and weight gain, particularly among the students in the age group between 17-25 years, which affects emotional status and physical appearance. Infertility, second major concern, particularly observed in females 25-30 years of age, as getting married and having children is a priority to Indians, and motherhood is a defining factor in a woman's status with the family and in social circles. 31,32

$64 \%$ of the respondents aware that changing in diet or eating habits can aid in PCOS out of which $88 \%$ altered their diet primarily in diet composition. Though aware in diet modification $12 \%$ participants did not modify their diet because they found it difficult to restrain to the diet, not interesting enough also, dieting takes a long time to show improvement and requires patience and perseverance which today's generation lacks in. $95 \%$ of the subjects concurred to follow life style modification besides their fertility drug and oral contraceptive pills that clearly indicates a need of multidisciplinary approach in managing PCOS involving medical and allied health professionals focusing on physical and psychological well-being of subjects with PCOS.

$100 \%$ of this study participant reported that they had not received any structured exercise program from any physiotherapist. This may be due to the fact that subjects were not aware that physiotherapist are involved in exercise prescription neither had been advised to consult however high level of evidence affirms structured exercise training improves an array of health-related outcomes not only physical also psychological well-being which includes protection against the development of cardio vascular disease and insulin sensitivity. ${ }^{33-36}$ Arun Maiya et al in reported that the graded aerobic exercise helps in reducing the cyst size, increasing the ovulation, pregnancy rate as compared to control group. A study by Nidhi R et al in observed holistic yoga program in PCOS helps in reducing anxiety symptoms. ${ }^{37}$ Physiotherapist are directly not only involved in exercise testing but also prescribing tailor made exercise program based on the patient needs and functional impairment. Absence of physiotherapist's contribution in the comprehensive management of PCOS is beyond the scope of this study. However participant's knowledge on PCOS having high proximity to their gynaecologist and /or physician. Physiotherapists need to bridge this gap by joining hands with medical practitioner in patient education, motivating them to adhere regular physical activity apart from need based exercise program and add evidence to the literature. Even academician need to inculcate evidence based practice of PCOS at an undergraduate physiotherapy program to improve demand supply ratio. This contemporary PCOS demands of multidisciplinary approach emphasis need to be placed on the life style modification as well. Furthermore this study can be explored identifying barriers in lifestyle modification also the effects of lifestyle modification in PCOS.

\section{CONCLUSIONS}

Efforts need to intensify in creating awareness on the general public about PCOS since more than $30 \%$ of the participants reported as "minimally aware" and "not at all aware" especially develop a strategy to reach to the lower socioeconomic strata. Irregular periods and weight gain was the major concern of our study participants and majority of them are anxious. Absolute majority of the study participants uncoerced to follow lifestyle modification however physiotherapist need to work along with the medical practitioner to sensitize PCOS population and prescribe need based structured exercise program for the better outcome. Hence this multifaceted presentation signifies need of multidisciplinary approach.

\section{ACKNOWLEDGEMENTS}

We are very thankful to all our participants who made our research possible. Grateful to the department of Biostatistics at our Institute for facilitating data analysis. Thankful to the almighty for providing immense strength to conduct this study.

Funding: No funding sources Conflict of interest: None declared

Ethical approval: The study was approved by the Institutional Ethics Committee 


\section{REFERENCES}

1. Hart R, Hickey M, Franks S. Definitions, prevalence and symptoms of polycystic ovaries and polycystic ovary syndrome. Best Practice and Research in Clinical Obstetrics and Gynaecology. 2004;18(5):671-83.

2. Paradisi G, Steinberg HO, Hempfling A, Cronin J, Hook G, Shepard MK, et al. Polycystic ovary syndrome is associated with endothelial dysfunction. Circulation. 2001;103:1410-5.

3. Solomon CG. The epidemiology of polycystic ovary syndrome. Prevalence and associated disease risks. Endocrinology and Metabolism Clinics of North America. 1999;28(2):247-63.

4. Deeks AA, Gibson-Helm ME, Teede HJ. Anxiety and depression in polycystic ovary syndrome: A comprehensive investigation. Fertil Steril. 2010;93(7):2421-3.

5. Himelein MJ, Thatcher SS. Polycystic ovary syndrome and mental health: A review. Obstet Gynecol Surv. 2006;61(11):723-32.

6. Oddens BJ, Den TI, Nieuwenhuyse H. Psychosocial experiences in women facing fertility problems - a comparative survey. Human Reproduction. 1999;14(1):255-61.

7. Azziz R, Zacur HA. Polycystic ovary syndrome. In: Wallach EE, Zacur HA, eds. Reproductive Medicine and Surgery. St. Louis, Mo: Mosby-Year Book, Inc. 1995:230-49.

8. Thomson RL, Buckley JD, Brinkworth GD. Exercise for the treatment and management of overweight women with polycystic ovary syndrome. Obes Rev. 2011;12(5):e202-10.

9. Van der Spuy ZM, Dyer SJ. The pathogenesis of infertility and early pregnancy loss in polycystic ovary syndrome. Best Pract Res Clin Obstet Gynaecol. 2004;18(5):755-71.

10. Boomsma CM, Eijkemans MJ, Hughes EG, Visser GH, Fauser BC, Macklon NS. A meta-analysis of pregnancy outcomes in women with polycystic ovary syndrome. Hum Reprod Update. 2006;12(6):673-83.

11. Ching HL, Burke V, Stuckey BG. Quality of life and psychological morbidity in women with polycystic ovary syndrome: body mass index, age and the provision of patient information are significant modifiers. Clin Endocrinol (Oxf). 2007;66(3):373-9.

12. Himelein MJ, Thatcher SS. Depression and body image among women with polycystic ovary syndrome. J Health Psychol. 2006;11(4):613-25.

13. Barnard L, Ferriday D, Guenther N, Strauss B, Balen AH, Dye L. Quality of life and psychological wellbeing in polycystic ovary syndrome. Hum Reprod. 2007;22(8):2279-86.

14. Norman RJ, Davies MJ, Lord J, Moran LJ. The role of lifestyle modification in polycystic ovary syndrome. Trends Endocrinol Metab. 2002;13(6):251-7.

15. Moran LJ, Brinkworth G, Noakes M, Norman RJ. Effects of lifestyle modification in polycystic ovarian syndrome. Reprod Biomed Online. 2006;12(5):56978.

16. Galletly C, Moran L, Noakes M, Clifton P, Tomlinson L, Norman R. Psychological benefits of a high-protein, low carbohydrate diet in obese women with polycystic ovary syndrome- a pilot study. Appetite. 2007;49(3):590-3.

17. Mavropoulos JC, Yancy WS, Hepburn J, Westman EC. The effects of a low-carbohydrate, ketogenic diet on the polycystic ovary syndrome: a pilot study. Nutr Metab (Lond). 2005;2:35.

18. Cussons AJ, Stuckey BG, Walsh JP, Burke V, Norman RJ. Polycystic ovarian syndrome: marked differences between endocrinologists and gynaecologists in diagnosis and management. Clin Endocrinol (Oxf). 2005;62(3):289-95.

19. Norman R, Davies M, Lord J, Moran LJ. The role of lifestyle modification in polycystic ovary syndrome. Trends Endocrinol Metab. 2002;13:251-7.

20. Maiya AG, Sheela RK, Kumar P. Exercise-Induced Weight Reduction and Fertility Outcomes in Women with Polycystic Ovarian Syndrome who are Obese and Infertile: A Preliminary Report. Journal of Exercise Science and Physiotherapy 2008;4(1):30-4.

21. Wahrenberg H, Ek I, Reynisdottir S, Carlstrom K, Bergqvist A, Peter Arner. Divergent effects of weight reduction and oral anticonception treatment on adrenergic lipolysis regulation in obese women with the polycystic ovary syndrome. Journal of Clinical Endocrinology and Metabolism 1999;84(6):2182-7.

22. Azziz R, Woods KS, Reyna R, Key TJ, Knochenhauer ES, Yildiz BO. The prevalence and features of the polycystic ovary syndrome in an unselected population. J Clin Endocrinol Metab. 2004;89(6):2745-9.

23. Colwell K, Lujan ME, Lawson KL, Pierson RA, Chizen DR. Women's perceptions of polycystic ovary syndrome following participation in a clinical research study: implications for knowledge, feelings, and daily health practices. J Obstet Gynaecol Can. 2010;32(5):453-9.

24. Cheryce LH, Catherine BL, Lisa JM, Helena JT. Exercise therapy in polycystic ovary syndrome: a systematic review. Human Reproduction Update. 2011;17(2):171-83.

25. Dunaif A, Thomas A. Current concepts in the polycystic ovary syndrome. J Annual Review of Medicine. 2001;52:401-19.

26. Sundararaman PG, Shweta, Sridhar GR. Psychosocial Aspects of Women with Polycystic Ovary Syndrome from South India. Journal of Association of Physicians of India. 2008;56(12):9458.

27. Li L, Yang D, Chen X, Chen Y, Feng S, Wang L. Clinical and Metabolic Features of Polycystic Ovary Syndrome. International Journal of Gynecology and Obstetrics. 2007;97(2):129-34. 
28. Allahbadia GN, Merchant R. Polycystic Ovary Syndrome in the Indian Subcontinent. Seminars in Reproductive Medicine. 2008;26(1):22-34.

29. Nidhi R, Padmalatha V, Amritanshu R. Prevalence of polycystic ovarian syndrome in Indian adolescents. J Pediatr Adolesc Gynecol. 2011;24(4):223-7.

30. Scott Sills E, Mark P, Michael JT, Carolyn RK, Marc GG, Glenn LS. Diagnostic and treatment characteristics of polycystic ovary syndrome: descriptive measurements of patient perception and awareness from 657 confidential self-reports; BMC Women's Health. 2001;1:3.

31. Mehta B, Kapadia S. Experiences of Childlessness in an Indian Context: A Gender Perspective. Indian Journal of Gender Studies. 2008;15(3):437-60.

32. Widge A. Seeking Conception: Experiences of Urban Indian Women with in Vitro Fertilisation. Patient Education and Counselling. 2005;59(3):22633.

33. Jakicic JM, Otto AD. Treatment and prevention of obesity: what is the role of exercise? Nutr Rev 2006;64(2):S57-61.

34. Lynch J, Helmrich SP, Lakka TA, Kaplan GA, Cohen RD, Salonen R, et al. Moderately intense physical activities and high levels of cardiorespiratory fitness reduce the risk of noninsulin-dependent diabetes mellitus in middleaged men. Arch Intern Med. 1996;156(12):1307-14.

35. Manson JE, Greenland P, LaCroix AZ, Stefanick ML, Mouton $\mathrm{CP}$, Oberman A, et al. Walking compared with vigorous exercise for the prevention of cardiovascular events in women. N Engl J Med. 2002;347(10):716-25.

36. Lee IM, Hsieh CC, Paffenbarger RS Jr. Exercise intensity and longevity in men. The Harvard Alumni Health Study. JAMA. 1995;273(15):1179-84.

37. Nidhi R, Padmalatha V, Nagarathna R, Amritanshu R. Effect of holistic yoga program on anxiety symptoms in adolescent girls with polycystic ovarian syndrome: A randomized control trial. Int $\mathrm{J}$ Yoga. 2012;5(2):112-7.

Cite this article as: Pitchai P, Sreeraj SR, Parmar RA. Awareness of lifestyle modification in females diagnosed with polycystic ovarian syndrome in India: explorative study. Int J Reprod Contracept Obstet Gynecol 2016;5:470-6. 